\begin{tabular}{l|l}
\hline \\
& SISTEMA \\
ELETONICO \\
DE REVISTAS \\
SER I UFPR
\end{tabular}

\title{
Editorial
}

\section{Comunicação e Mudanças Climáticas: uma discussão necessária e urgente}

\section{Communication and Climate Change: a necessary and urgent discussion}

As Mudanças Climáticas (MCs) são uma - ou, segundo muitos, são mesmo "a" - questão socioambiental central do nosso tempo (e.g. Union of Concerned Scientists, 2017), não apenas por ser um fenômeno de alcance global e com impactos de enorme gravidade, mas por estarem relacionadas com uma série de outros desafios das sociedades contemporâneas, como conservação da biodiversidade, segurança alimentar, produção e consumo de energia, refugiados ambientais, entre outros.

As emissões de gases de efeito estufa geradoras das MCs estão associadas a múltiplas práticas características dos modos e estilos de vida modernos, como o consumo ilimitado, algo que é visto como garantido por muitos no planeta e a que muitos mais continuam a aspirar. Desse modelo socioeconômico-cultural, alimentado diariamente por cerca de 100 milhões de barris de petróleo e por mais de 20 megatoneladas de carvão (IEA, 2017a; 2017b), emergem, para além de várias formas de poluição, iniquidades sociais e injustiças internacionais e intergeracionais. As MCs são, portanto, uma questão que engloba dimensões econômicas, políticas, sociais, éticas e muitas outras. Imaginar formas de mitigação significativas das MCs é necessariamente imaginar um futuro muito diferente, em que as sociedades precisariam se reorganizar em diferentes níveis. Daí se torna óbvio que o engajamento público é fundamental para se construir democraticamente um futuro mais sustentável (Carvalho \& Peterson, 2012).

Por ser um problema urgente, com diversos impactos sociais, o papel da imprensa faz-se imprescindível, já que é por meio dela que os cidadãos podem tomar conhecimento das causas e consequências das MCs, não apenas sob o enfoque científico, mas percebendo suas conexões com a política, economia e cultura. A relação entre Comunicação e Mudanças Climáticas é crucial para o enfrentamento de seus riscos, especialmente se pensarmos que as pessoas só perceberão alguns efeitos invisíveis das MCs, em curto prazo, por intermédio dos discursos divulgados pela imprensa. É na mídia e em outras arenas de comunicação que se definem e redefinem os sentidos das MCs e se confrontam argumentos, valores e visões do mundo em torno da questão 
(Hulme, 2009). Por isso, a comunicação é essencial à participação das pessoas nos debates públicos e nas decisões políticas.

Analisar as vozes e os discursos midiáticos permite reconhecer quais tipos de perspectivas são legitimadas e normalizadas. Ao mesmo tempo, é importante identificar os silêncios e as omissões, ou seja, as alternativas às visões hegemônicas, que são ocultadas. Para além disso, importa perceber se essas alternativas estão sendo debatidas em outros espaços e plataformas de comunicação.

Na Europa, Estados Unidos, Austrália e Nova Zelândia, as pesquisas sobre as representações das MCs começaram, na generalidade, na década de 1990. Os estudos têm predominantemente incidido sobre os países "ocidentais", "ricos" e "democráticos", em particular a Europa e a América do Norte. Schäfer \& Schlichting (2014) mostram que muito pouco tem sido publicado sobre o tema na América Latina e na África, sendo que se encontram aí regiões altamente vulneráveis aos impactos das MCs.

No Brasil, os primeiros trabalhos, ainda pontuais, voltados para a interface entre comunicação e meio ambiente são oriundos de pesquisadores interessados em comunicação científica nos anos 1990. A partir da metade dos anos 2000 há um esforço mais sistemático por parte de alguns autores (e.g. Girardi et al., 2006; Bueno, 2007) nas investigações de jornalismo ambiental, sendo que as MCs, como objeto central do estudo, ganharam repercussão a partir de uma pesquisa que analisou a cobertura do tema em 50 jornais de diferentes estados (Vivarta, 2010). Mesmo com o início das pesquisas sobre Comunicação e MCs, estas ocorrem de forma descontinuada e pouco articulada, sendo resultado de interesses individuais. Tal realidade é ainda mais evidente no País, onde há ausência de financiamentos e estímulos para o fomento de investigações na área das Ciências Sociais e Huma- nas, e as propostas interdisciplinares nem sempre contemplam a perspectiva comunicacional.

Este dossiê da revista Desenvolvimento e Meio Ambiente procura colaborar com a disseminação das discussões mais recentes que estão sendo realizadas em torno do binômio já citado. Grande parte do que foi produzido até agora é resultante de esforços de falantes de língua inglesa e focados em jornais (Shanahan, 2009), por isso a importância deste trabalho, com muitos textos em português e voltado não apenas para a cobertura midiática em impressos, mas também para as redes sociais, os webjornais e as percepções das pessoas sobre a representação da imprensa, entre outros recortes. O dossiê temático oferece aportes importantes para responder, entre outras, às seguintes perguntas: De que forma a mídia tem contribuído para o reforço do status quo em relação a visões e políticas relevantes para as MCs ou, pelo contrário, tem impulsionado a mudança? Até que ponto os discursos dominantes têm promovido o engajamento dos cidadãos com a questão? Quais discursos podem ser identificados em meios e espaços alternativos de comunicação?

Sendo universalmente pertinentes, essas questões precisam sempre ser analisadas a partir dos contextos concretos em que a comunicação tem lugar. A responsabilidade do Brasil relativamente às MCs está fortemente associada aos usos da terra. O primeiro artigo deste dossiê, de autoria de Myanna Lahsen, expõe o grave silêncio da mídia brasileira a respeito da conexão entre as MCs e a criação de gado bovino ou, em outras palavras (mais apropriadas para os públicos e para as suas decisões de consumo), o consumo de carne. Apesar de a comunidade científica brasileira calcular que cerca de metade das emissões nacionais de gases de efeito estufa está ligada a esse setor, a análise dos jornais $O$ Estado de S. Paulo e Folha de S.Paulo mostra que a questão é marginalizada, havendo um 
enfoque quase exclusivo em questões energéticas na cobertura das MCs. Os jornalistas suprimem, assim, do olhar público um fator determinante para o País, que poderia contribuir eficazmente para reduzir as emissões de gases de efeito estufa. Essa opção jornalística pode ocorrer em razão do poder (simbólico, financeiro, etc.) de determinados agentes sociais e do papel da carne na cultura (alimentar) brasileira.

As investigações em vários países mostram que as MCs, como outros desafios ambientais, têm sido predominantemente enquadradas como problemas que podem ser "resolvidos" com soluções técnicas (Swyngedouw, 2011), que permitiriam prescindir de mudanças socioculturais mais estruturais. Neste dossiê, Claudia Herte Moraes esmiúça uma reportagem especial da cobertura da Rio+20 pela revista Época, com o intuito de compreender de que forma o discurso sobre as MCs articula a noção de futuro e, por consequência, a relação homem-natureza subjacente. Apoiada na Análise do Discurso da linha de Michel Pêcheux e nas Teorias do Jornalismo construcionistas, indica o enquadramento discursivo como dispositivo de análise e mostra como uma visão ecotecnocrática das MCs ocupa uma posição hegemônica.

O discurso jornalístico não é necessariamente homogêneo na reconstrução discursiva que faz das MCs nas suas múltiplas facetas e escalas. Comparando a imprensa brasileira com a imprensa francesa ao longo de vários anos, o artigo de Ana Carolina Peliz emprega as noções de utopia e distopia para discutir a representação do conhecimento científico, as posições políticas e outros aspetos relacionados às MCs. Em ambos os países, os jornais simplificam excessivamente as relações políticas internacionais e da ciência, ao mesmo tempo em que propagam a ideia de natureza intocada, lugar-santuário, que, na nova era geológica do Antropoceno (Swyngedouw, 2011), deixa inevitavelmente de ser. Por outro lado, e no mesmo sentido que a reflexão desenvolvida por Cláudia Herte Moraes, Ana Carolina Peliz aponta que a tecnologia é perspectivada pela imprensa como meio de salvação da humanidade.

Myrian Del Vecchio de Lima, Mônica Fort, Otávio Cezarini Ávila, Augusta Gern e Manoella Fortes Fiebig realizam também um estudo comparativo internacional, centrado na cobertura da COP-21 no The Huffington Post, em suas versões norte-americana, francesa e brasileira. Os autores identificam as ênfases que mais se evidenciaram nas notícias sobre esse evento, buscando analisar se o leitor pode ser levado à sensação de medo ou, ao contrário, a uma sensibilização que possa estimular o enfrentamento dos riscos climáticos.

Os discursos da mídia sobre as MCs serão melhor compreendidos se, como recomendam Olausson e Berglez (2014), além do estudo de conteúdos/textos midiáticos, se analisar o processo de produção jornalística. $\mathrm{O}$ artigo de Caroline Rodas e Gabriela Di Giulio apresenta resultados de uma pesquisa que partiu do exame de jornais impressos e de entrevistas com jornalistas de São Paulo que cobrem MCs, com atenção especial a sua articulação com questões energéticas. As autoras discutem os resultados à luz de três argumentos analíticos: 1) a tendência a uma cobertura jornalística mais centrada em eventos e acontecimentos pontuais; 2) as mudanças na abordagem da cobertura sobre MCs ao longo dos anos; e 3) a adoção de critérios de noticiabilidade na seleção das informações divulgadas e na cobertura sobre mudanças climáticas, incluindo senso de oportunidade, interesse (pelo) humano e conflito.

Com um pendor assumidamente normativo, o artigo de Yves Pepermans e Pieter Maeseele problematiza as opções jornalísticas sobre MCs, por meio de uma crítica da cobertura midiática dominante, evidenciando ser enviesada por uma pretensa 
objetividade e por critérios de noticiabilidade, como novidade, personificação e dramatização. Pepermans e Maeseele focalizam-se em exemplos de jornalismo "alternativo" na Bélgica e Holanda e na forma como os seus autores refletem sobre as $\mathrm{MCs}$, bem como sobre os problemas na cobertura da mídia convencional. A postura agonística nesses meios alternativos investe numa "lógica de contestação" que dá conta de questões de poder e de diferenças ideológicas nos discursos e propostas sobre as MCs. Essa politização do debate mostra que existem diferentes possibilidades de ação e que o futuro depende de escolhas coletivas - e, portanto, políticas -, sendo tendencialmente empoderadora dos leitores/cidadãos.

A expansão da comunicação online nas últimas décadas levou vários pesquisadores a se interrogarem sobre o debate em torno das MCs, o qual tem lugar nesses espaços de comunicação sem intermediação (de jornalistas, editores ou outros profissionais), como as redes sociais, blogs e diferentes tipos de páginas web (e.g. Kirilenko \& Stepchenkova, 2014). No artigo que publicam neste dossiê, Alice Balbé e Anabela Carvalho verificam quais conteúdos são mais populares e qual é a linguagem utilizada para se debater o tema no site de microblogging Twitter. Com base em posts em português e em espanhol, realizam também o mapeamento dos atores que formam esta rede, identificando aqueles que são mais influentes: a mídia convencional e os atores políticos. Apesar de a influência na rede (medida com base nos perfis mais citados) reproduzir e fortalecer a distribuição de poder fora dela, nos dados em português, os perfis mais ativos são de cidadãos e grupos cívicos, o que sugere um engajamento significativo com a questão das MCs.

Os dois artigos seguintes recorrem a questionários para analisar os modos como os cidadãos percebem as MCs. O artigo apresentado por Liliana
Oliveira e Anabela Carvalho preocupa-se com a mobilização dos cidadãos frente às MCs e as formas de melhor envolvê-los para sua participação efetiva. Para tanto, as autoras apresentam os resultados de um estudo de percepção com espanhóis e portugueses sobre a importância da sua ação neste contexto e os fatores que influenciam o seu envolvimento com o tema, bem como as barreiras que os constrangem. O texto assinado por Hellen Chrystianne Barros e José de Queiroz Pinheiro se debruça sobre a percepção dos adolescentes a respeito das MCs e de sua associação com práticas de cuidado ambiental autorrelatadas em escolas de Natal (RN). O desenvolvimento dessa pesquisa está articulado à promoção de medidas de educação ambiental, a fim de ampliar o escopo de ações praticadas pelos adolescentes, incluindo outras ações de mitigação do problema em nível local.

Finalmente, Gabriela Litre, Melissa Curi, Patricia S. Mesquita, Stéphanie Nasuti e Gledson Rocha apresentam os desafios de se comunicar os resultados de uma pesquisa científica realizada com agricultores familiares do semiárido nordestino um dos segmentos da população brasileira mais vulnerável às $\mathrm{MCs}$-, a partir da exposição do processo de elaboração e de divulgação de uma cartilha educativa sobre as percepções desses sujeitos, as medidas de adaptação que estão sendo implementadas na região e uma explicação sobre o clima na Região Nordeste e suas variabilidades climáticas.

Esperamos que esta coleção de artigos permita avançar o debate sobre as conexões entre Comunicação e Mudanças Climáticas, além de servir de estímulo para o desenvolvimento de novas pesquisas. Apreciem a leitura!

Eloisa Beling Loose Anabela Carvalho Organizadoras 


\section{Referências}

Bueno, W. Comunicação, jornalismo e meio ambiente: teoria e pesquisa. São Paulo: Majoara, 2007.

Carvalho, A.; Peterson, T. R. (Eds.). Climate change politics: communication and public engagement. Amherst, NY: Cambria Press, 2012.

Girardi, I. M. T.; Massierer, C.; Schwaab, R. T. Pensando o Jornalismo Ambiental na ótica da Sustentabilidade. Unirevista, 1(3), 1-10, 2006.

Hulme, M. Why we disagree on climate change: Understanding controversy, inaction and opportunity. Cambridge: Cambridge University Press, 2009.

IEA - International Energy Agency. Coal. Disponível em: $<$ https://www.iea.org/about/faqs/coal/>. Acesso em: fev. 2017 a.

IEA - International Energy Agency. Oil. Disponível em: $<$ http://www.iea.org/about/faqs/oil/>. Acesso em: fev. 2017b.

Kirilenko, A. P.; Stepchenkova, S. O. Public microblogging on climate change: One year of Twitter worldwide. Global Environmental Change, 26, 171-182, 2014. doi: 10.1016/j. gloenvcha.2014.02.008

Olausson, U.; Berglez, P. Media and climate change: Four long-standing research challenges revisited. Environmental Communication, 8(2), 249-265, 2014. doi: $10.1080 / 17524032.2014 .906483$
Schäfer, M; Schlichting, I. Media representations of climate change: A meta-analysis of the research field. Environmental Communication, 8(2), 142-160, 2014. doi: 10.1080/17524032.2014.914050

Shanahan, M. Time to adapt? Media Coverage of Climate Change in Nonindustrialised Countries. In: Boyce, T.; Lewis, J. Climate Change and the Media. New York: Peter Lang Publishing, p. 145-157, 2009.

Swyngedouw, E. Whose environment? The end of nature, climate change and the process of post-politicization. Ambiente \& Sociedade, 14(2), 2011. doi: 10.1590/S1414753X2011000200006

Union of Concerned Scientists. Global warming impacts: the consequences of climate change are already here. Disponível em: <http://www.ucsusa.org/our-work/global-warming/science-and-impacts/global-warming-impacts\#. WJ8gjiOLSpc>. Acesso em: fev. 2017.

Vivarta, V. (Coord.). Mudanças climáticas na imprensa brasileira: uma análise comparativa de 50 jornais nos períodos de julho de 2005 a junho de 2007- julho de 2007 a dezembro de 2008 (Relatório de Pesquisa/2010). Brasília, DF, Agência de Notícias dos Direitos da Infância (ANDI), 2010. Disponível em: < https://issuu.com/andi_midia/docs/ mudancas_climaticas_na_imprensa_brasileira_200507>. Acesso em: fev. 2017. 